\title{
The power of home rehabilitation: a single case study
}

Rebecca Lackie, Leanne Bisset

This single case study reports on an 81-year old woman who underwent a rehabilitation programme initially in a hospital inpatient setting, then in a home setting. There was a clinically significant improvement in functional outcomes following the home-based rehabilitation, but not following the inpatient rehabilitation programme. This case study illustrates that empowerment of the patient may sometimes be greater in the home environment, possibly due to different roles taken by the patient and therapist in the home compared with roles taken in a hospital environment. This patient reported feelings of being in more control at home, with greater capacity to set their own goals, and improved feelings of motivation with this increased level of engagement. This increased empowerment can lead to more effective outcomes for patients undergoing rehabilitation in the home, and must be considered as an ideal rehabilitation environment for some patients.

Key words: $\mathbf{\square}$ inpatients $\square$ aged $\square$ rehabilitation $\square$ home care services

Submitted 16 May 2012, sent back for revisions 29 June 2012; accepted for publication following double-blind peer review 28 September 2012

A ustralia's current ageing population and increases in the average life span (Authoritative information and statistics to promote better health and wellbeing (AIHW), 2007) have placed increasing pressure on hospitals and rehabilitation services. These pressures have led the health care industry to focus on strategies to reduce admissions and inpatient length of stay, especially for non-acute or rehabilitative care (AIHW, 2007). In addition, this pressure on the health care system has facilitated the initiation of programmes to minimise premature admissions into aged care facilities, and ensure older people do not wait unnecessarily in hospital for a residential aged care placement (Flinders Consulting, 2008). In order to do this there must be adequate low-intensity care (including care at home) to meet demand in a timely way (Dwyer and Jackson, 2001).

Several researchers have looked at rehabilitation in the home as a viable option to inpatient care. It has been found that providing rehabilitation in the home reduces inpatient length of stay without compromising patient outcomes (Anderson et al, 2000a; 2000b). A literature review of the current accommodation preferences for older adults reported that they prefer to remain at home, with few deeming nursing homes as an acceptable option (Eckert et al, 2004). Individuals consider their home to be a safe place to return to for rest and recovery, and a place where they can manage on their own terms. People residing in their own home had strong motivation to maintain their health, and were confident in challenging themselves and taking action to maintain their health within the familiarity of their home environment (Fänge and Ivanoff, 2009). It has also been stated that providing rehabilitation services in the patient's home environment is associated with improved community reintegration and physical outcomes (Mayo et al, 2000).

While the older population have reported positive feelings associated with living in their own home, the link between the home environment and rehabilitation outcomes in a pain population has not been reported. This single case study describes a longitudinal time series of care and outcomes for an 81-year-old lady with chronic low back pain, who underwent both inpatient and home-based rehabilitation for chronic back pain and general loss of function. Furthermore, it highlights the differences in outcomes between inpatient rehabilitation that was deemed ineffective versus home-based rehabilitation that was effective in an individual who was deemed best suited to a high care nursing facility.

\section{Ethics}

Ethics approval was granted from the Human Research Ethics Committee, Gold Coast Health Services District, and written informed consent was obtained from Mrs $\mathrm{O}$ to use her case for publication.
Rebecca Lackie is a Physiotherapist, Transition Care Program, Gold Coast Hospital and Health Service, Australia and;

Leanne Bisset is

Research Fellow, School of Physiotherapy and Exercise Science, Griffith University, Gold Coast Campus, Australia

Correspondence to:

Rebecca Lackie

E-mail: Rebecca lackie@health.qld.gov.au 


\section{CASE HISTORY}

Mrs $\mathrm{O}$ is an 81 year-old married female with a 10-year history of chronic low back pain. Her past medical history included a laminectomy (2003), a spinal fusion (November 2009) and a surgical revision (March 2010). Her medical history included osteoporosis and hypertension. She was mobilising independently with a fourwheeled walker following each of her surgeries, however she reported increasing back pain, deteriorating mobility and an inability to cope at home, when she presented to accident and emergency at a private hospital on 30 April 2010.

\section{Inpatient rehabilitation}

Mrs $\mathrm{O}$ was admitted as an inpatient with severe low back pain and prescribed oral controlled release oxycodone and transdermal fentanyl to manage her pain. She was also given immediate release oxycodone for breakthrough pain. The oral morphine equivalent dosage was $500 \mathrm{mg}$ every 24 hours (Therapeutic Guidelines Limited, 2012). Mrs O was an inpatient of this private hospital for six weeks, during which time she spent four weeks undergoing multidisciplinary rehabilitation. Mrs $\mathrm{O}$ and her husband reported that interventions included three weeks of five times per week physiotherapy sessions. This consisted of bed exercises to improve lower limb muscle strength, upright postures on a tilt table, and hydrotherapy. This period of rehabilitation was unsuccessful in adequately managing her pain, and Mrs O's husband reported that the medications appeared to impair Mrs O's cognition and level of arousal. As a result, Mrs O's impaired cognition and low level of arousal interfered with her ability to participate in her therapy sessions. She was confined to bed and an in-dwelling catheter was inserted due to urinary incontinence, which was thought to be associated with her poor mobility. Mrs O's mobility continued to deteriorate, and shortly after admission she required a hoist to transfer. During her inpatient stay, Mrs O required full assistance with all her personal activities of daily living. After six weeks as an inpatient, it was recommended by the treating health staff that Mrs $\mathrm{O}$ be transferred to a high-care residential nursing facility, as no further improvement in her functional capacity was anticipated. In consultation with her family and husband, Mrs O requested to continue her inpatient care and was then transferred to a sub-acute public health facility for further rehabilitation interventions.

On admission to this second rehabilitation facility, Mrs O's mobility status continued to require hoist transfers and use of a wheelchair with full assistance. She rated 0 out of 23 on the Modified Elderly Mobility Scale (MEMS), a validated population-specific questionnaire rating an individual's general mobility status (Kuys and Braur, 2006). This scale gives a score for differing components of mobility, including moving from a lying to a sitting position, standing up, standing balance, walking, reaching and climbing stairs. On admission, Mrs $\mathrm{O}$ was unable to complete any of the tasks listed in the MEMS.

Mrs $\mathrm{O}$ remained an inpatient of this subacute facility for four months, during which time her medications were altered from a combination of transdermal fentanyl and controlled release oxycodone to gabapentin and controlled release oxycodone. It is important to note that at this point, Mrs $\mathrm{O}$ was now on $75 \mathrm{mg}$ oral morphine equivalent every 24 hours (Therapeutic Guidelines Limited, 2012). Her husband reported this change to her medications markedly improved Mrs O's level of alertness. Also during this time, Mrs O received up to five sessions each, per week, of physiotherapy, social work and occupational therapy. The physiotherapy sessions included task specific training, bed exercises, transfer practice and sit to stand practice, while the occupational therapist worked on improving activities of daily living, including power wheelchair practice, showering and dressing. Despite this high intensity rehabilitation programme, Mrs $\mathrm{O}$ failed to make clinically important improvements in her overall function, and at six weeks prior to her discharge, it was decided that Mrs $\mathrm{O}$ would remain a hoist transfer. The physiotherapist ceased working on task training, transfers or standing practice, and focussed on bed exercises and hoist transfer practice. The frequency of the rehabilitation sessions decreased to three times per week at this point. Mrs O continued to require a hoist for all transfers and, due to her lack of functional improvement, was considered unlikely to ever walk again by the health care team. Once again, the treating team expressed concern about Mrs O's capacity to be discharged home, and recommended she would be better suited to a high-care nursing facility.

$\mathrm{Mr}$ and $\mathrm{Mrs} \mathrm{O}$, in consultation with the health care team, considered their options and chose to have Mrs O discharged home. An occupational therapist assisted them with extensive home modifications and equipment, including a ceiling-track hoist and sling, a power wheelchair, a hospital bed with a pressure mattress, bed linen, bathroom modifications, a floor 


\section{AQ1: This table needs a heading.}

wedge to allow access of the wheelchair to the outside balcony, a shower chair, and hand rails. These modifications and equipment, although government subsidised, involved a substantial financial commitment from Mrs $\mathrm{O}$ and her family to the sum of $\$ 22000$. On review, the medical team decided Mrs O's in-dwelling catheter would remain permanently in situ due to her continuing immobility. On 24 October 2010, Mrs $\mathrm{O}$ was discharged home into the care of her husband with a referral to the community rehabilitation team.

\section{Home-based rehabilitation}

Mrs O was initially assessed at home by the community rehabilitation physiotherapist on the day of discharge from the inpatient facility. Her overall level of physical function was extremely low, with a score of $0 / 23$ on the MEMS and a score of 31/100 on the Modified Barthel Index (MBI). The MBI is a functional rating scale which records the level of disability during ten activities of daily living (ADLs) (Wade and Collin, 1987). ADLs include personal hygiene, bathing, feeding, stair climbing, dressing, bladder and bowel control, walking and transfers. A score of 31 placed her in the category of severe dependence (Shah et al, 1989). When questioned regarding her goals, Mrs O reported that her primary goal was to walk. Considering Mrs O's preferences and her level of physical disability, it was decided that a home-based rehabilitation programme would be implemented, which was task-focused and patient-centred in its approach.

Mrs $\mathrm{O}$ underwent a multidisciplinary homebased rehabilitation programme for 18 weeks. The primary focus was on improving Mrs O's level of physical function, for which she received 2-3 sessions per week of physiotherapy, with each session lasting approximately one hour. In addition, Mrs $\mathrm{O}$ received five sessions of occupational therapy for activity of daily living assessment and treatment, four reviews by a clinical nurse for management of the catheter, and three sessions by the social worker for emotional support.

A functional approach in the home was adopted and short-term achievable goals were worked on, which has previously been shown to improve a person's level of confidence when carrying out a certain task (Lee et al, 2008). Using this approach assisted Mrs O to break down her primary goal of walking into smaller goals while remaining task-oriented (Table 1) (Rensink et al, 2009). The components required to achieve each activity were practiced in isola-

\begin{tabular}{|c|c|}
\hline Goal set by Mrs 0 & $\begin{array}{l}\text { Time goal achieved from } \\
\text { commencement of the } \\
\text { home-based rehabilitation } \\
\text { programme }\end{array}$ \\
\hline Stand at the rail for lower limb dressing & Week 4 \\
\hline Use a slide board for all transfers & Week 5 \\
\hline Complete car transfers with assistance & Week 6 \\
\hline Stand step transfer with assistance & Week 7 \\
\hline Walk with a forearm support frame & Week 8 \\
\hline Walk with a 4-wheeled walker indoors & Week 11 \\
\hline Toilet independently & Week 12 \\
\hline Walk with a 4-wheeled walker outdoors & $\begin{array}{l}\text { Week } 18 \text { required occasional } \\
\text { supervision for slopes and } \\
\text { obstacles only. }\end{array}$ \\
\hline Climb stairs & Week 18 with use of a hand rail. \\
\hline Remove urinary catheter & $\begin{array}{l}\text { Week } 20 \text { ( } 2 \text { weeks post-discharge } \\
\text { from home programme) }\end{array}$ \\
\hline $\begin{array}{l}\text { Sleep in her own bed (previously slept } \\
\text { on a pressure mattress in a hospital- } \\
\text { style bed) }\end{array}$ & $\begin{array}{l}\text { Week } 20 \text { ( } 2 \text { weeks post-discharge } \\
\text { from home programme) }\end{array}$ \\
\hline
\end{tabular}

tion and then put together to practice the complete task. For example, an initial goal was to stand at a hand rail for 30 seconds, which would allow her carer to assist her with lower limb dressing as well as progress her level of function towards her walking goal. The exercises and shorter-term goals to achieve this primary functional goal included strengthening exercises for hip extension, knee extension and core stability were practised, as well as sit-to-stand practice, followed by standing balance with supported upper limbs, gradually increasing length of time in standing.

The treating physiotherapist ensured that education regarding the purpose of each exercise was given, to assist in compliance of Mrs $\mathrm{O}$ with the home rehabilitation programme. This was considered important, as one of Mrs O's main thoughts for why her inpatient rehabilitation programme failed, was that she did not understand the exercises she was given, or what they were trying to achieve. Mr and Mrs $\mathrm{O}$ would complete the exercises and the task specific training at least twice per day. Mrs O accomplished her first goal of standing at a hand rail within one week of commencing her home programme. As Mrs O achieved one goal, a new one was set. Using this approach, Mrs O's progress continued, with successful completion of a slideboard transfer through exercises prescribed to improve her trunk control as well as daily transfer practice using the slideboard. Table 1 shows the individual goals set and when each was achieved. 


\section{Outcomes}

On discharge, Mrs $\mathrm{O}$ was independently walking with a four-wheel walker, independently showering and toileting, and required minimal assistance with lower limb dressing. Her outcome measures had improved substantially, with MEMS and MBI scores placing her in the category of slight dependence (Figure 1). Mrs O's functional status was reviewed again at three weeks post-discharge from the homebased rehabilitation programme, when she reported being able to sleep in her own bed and having had the in-dwelling urinary catheter removed. At eight months follow up, Mrs O was still living at home with her husband, mobilising independently and attending to her activities of daily living independently or with minimal assistance from her husband.

\section{DISCUSSION}

This single case study reports the improvements in functional outcomes achieved using home based rehabilitation for an 81 year-old woman with chronic low back pain. After 22 weeks of inpatient care and no improvement in physical function, Mrs $\mathrm{O}$ went from extremely poor mobility and physical functioning to improvements that suggested she would be only slightly dependent on another person (Shah et al, 1989).

It must be noted that pain management medi-

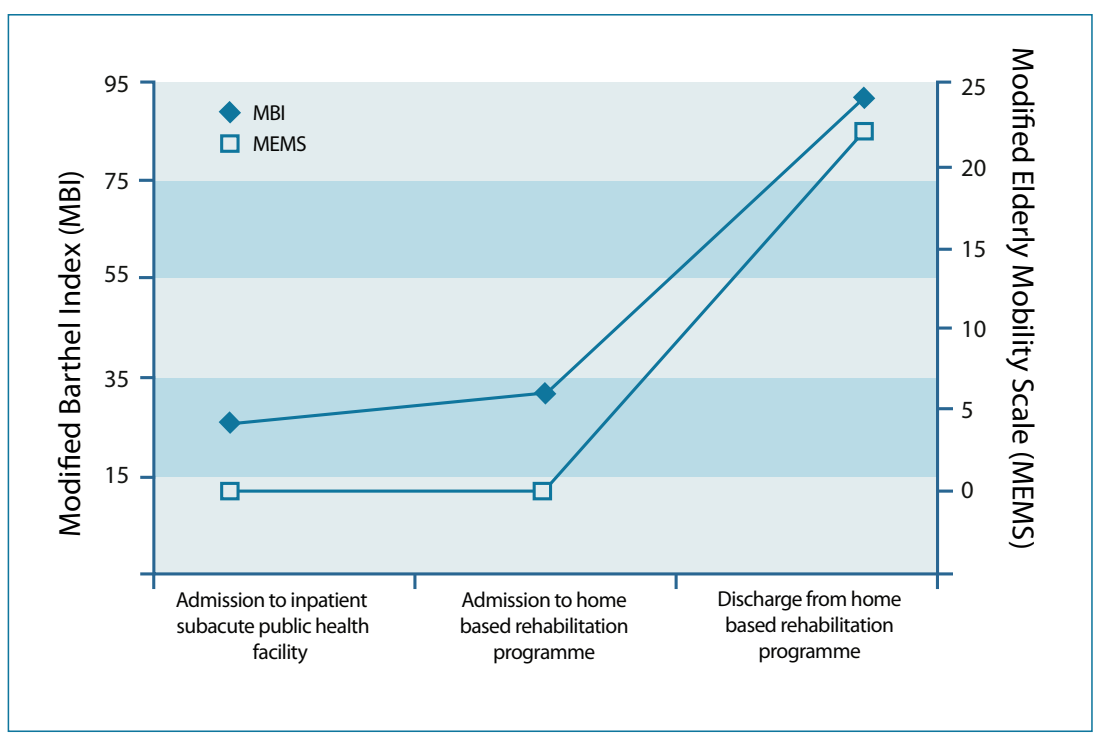

Figure 1. Patient functional scores for the Modified Barthel Index (MBI) (Wade and Collin, 1987) and the Modified Elderly Mobility Scale (MEMS) (Kuys and Braur, 2006) at admission to the inpatient subacute facility (7 weeks post-presentation to hospital emergency department, i.e. baseline), admission to the home based rehabilitation programme (25 weeks from baseline) and on discharge from the home based rehabilitation programme (43 weeks from baseline). cations were optimised soon after Mrs $\mathrm{O}$ was admitted to the second inpatient sub-acute facility. The introduction of gabapentin, as an adjuvant therapy, may have contributed to a reduction in Mrs O's level of pain, particularly if there was a neuropathic component (Dworkin et al, 2007). It is also noted that the opioid dose she received was greatly reduced. Her dose was approximately $500 \mathrm{mg}$ oral morphine equivalent (OME) every 24 hours on admission to the sub-acute facility. Following the introduction of gabapentin, the OME was reduced to approximately $75 \mathrm{mg}$ every 24 hours. Dose optimisation for gabapentin should occur within two weeks of its introduction, and a two-month trial period would be a reasonable timeframe within which maximum pain relief may be gained (Therapeutic Guidelines Limited, 2012). By introducing gabapentin and minimising the dosage of opioid medication, it would be expected that Mrs O's level of sedation, confusion, and pain would improve (Rossi, 2012), thereby allowing more effective participation in rehabilitation therapy. Despite this change to Mrs O's medication schedule, her level of function did not improve over the ensuing four-month inpatient setting. We may therefore consider that the causes of Mrs O's continuing functional deficits are multifactorial and not solely attributed to her ongoing pain. Similarly, as the medications, and therefore her pain levels, were optimised several months before her discharge home, Mrs O's improvements in her home environment may be attributable to factors other than improvements in her pain.

While it is readily accepted that chronic low back pain is a multifactorial biopsychosocial disorder (McCarthy et al, 2004 AQ2: This reference is not in the end list), pain severity and psychosocial factors such as catastrophising, kinesiophobia, depression and anxiety were not formally measured in this case study. The inclusion of these measures would greatly improve our understanding of the effect the environment (i.e. home versus hospital) may have on the biopsychosocial characteristics of chronic pain.

We acknowledge that Mrs O's home environment was optimised for safety and support of her carer. Significant equipment was installed in her home to assist with transfers and mobility around the house, as well as with her activities of daily living such as toileting and showering. Without the funds necessary to purchase this equipment and the availability of her husband to provide the ongoing care, it is unlikely that Mrs $\mathrm{O}$ would have been given the opportunity to try home-based rehabilitation. 
There were several differences between the home and inpatient rehabilitation programmes that may have contributed to differences in outcomes. For example, the timing and frequency of therapy may have influenced outcomes. The home-based rehabilitation activities occurred in short, frequent periods throughout the day with the assistance of her carer, and focused on the activities of daily living she required in order to remain living in her own home. In contrast, Mrs O's inpatient rehabilitation involved a maximum of a single daily session lasting approximately one hour. The patient reported that sessions were often missed due to conflicting schedules with other health staff, and time delays in obtaining assistance with dressing and hoist transfers.

$\mathrm{Mrs} \mathrm{O}$ and her carer were included in all decisions made regarding the home rehabilitation programme and were given appropriate explanations for each exercise. Mrs O reported that her participation in goal setting motivated her to be more compliant with the home programme. In contrast, Mrs $\mathrm{O}$ reported that, as an inpatient, she could not recall being given a reason or justification for the exercises, so she lacked understanding of the purpose of the programme. In addition, $\mathrm{Mrs} \mathrm{O}$ felt that she was not included in goal setting or the decision making process during her inpatient stay. It is difficult to determine if her lack of understanding of the inpatient rehabilitation programme was due to the lack of education from the treating therapists or her diminished cognition related to medications prescribed. Mrs O stated afterwards that she found it difficult to recall details from her inpatient stay, and that coming home felt like 'coming out of a fog'. It is possible that improved outcomes may have been achieved in the inpatient setting, if the rehabilitation programme had involved Mrs O's carer by enlisting him to assist with increased task practice during her inpatient stay. However, as the treating physiotherapist had deemed Mrs O to require a hoist transfer as an inpatient, the only time Mrs $\mathrm{O}$ was able to practice her transfers was once a day, five days a week, during her therapy sessions. While the hoist transfers were considered necessary for safety reasons, this lack of regular standing and transfer practice may have contributed to Mrs O's failure to demonstrate functional improvement during her inpatient stay.

Despite differences in approach, the underlying objectives of the rehabilitation programmes were similar between the inpatient and home settings, with a focus on task specific training in conjunction with strengthening exercises. The benefits of task specific training have been pre-

\section{KEY POINTS}

- A home-based rehabilitation programme was more effective at improving function than an inpatient rehabilitation programme.

- Home rehabilitation can empower the patient to feel more in control of their therapy then when they are in a hospital setting.

- Further work is needed in order to confirm these findings and to better understand the factors related to differences in biopsychosocial and functional outcomes, based on environment.

viously reported in the literature. For example, 12 weeks of task specific training such as sit-tostand from a bed or chair improved the ability to perform this task in impaired older adults (Alexander et al, 2001). Similarly, a repetitive functional training programme focusing on activities of daily living improved health status in older persons living in residential care facilities (Peri et al, 2007).

While there are limited high quality studies that have compared home versus hospital rehabilitation environments, there is preliminary evidence to suggest that home rehabilitation results in higher levels of function and satisfaction with greater community integration (Mayo et al, 2000), as well as significantly improved general health, MBI, and ADL scores, even at 12 months follow up (Cunliffe et al, 2004). Consistent with the anecdotal reports in our study, a qualitative study (Von Koch et al, 1998) comparing patient/therapist relationships in a home and hospital setting identified different role-sets, with the therapist taking the role of 'teacher' or 'expert' in the hospital, versus a shift between several roles including 'guest', 'friend', 'student' and 'teacher' in the home environment. These different role-sets may have contributed to the findings that patients who receive therapy in the home are empowered to take the initiative and communicate their own goals, compared to therapy received in a hospital setting (Von Koch et al, 1998). Furthermore, building rapport with a patient and involving them in goal setting have been shown to increase motivation and sense of control, decrease anxiety (Bloom et al, 2006), and improve patient assessment, treatment outcomes and satisfaction with treatment (Arnetz et al, 2004; Leach, 2005).

It appears that the home environment facilitates a stronger sense of engagement in the individual with a rehabilitation programme. One factor that may influence this level of engagement is the patient's level of self efficacy (Lee et 
al, 2008). The stronger a person believes in their ability to perform an activity, the more likely they will be to initiate and persist in the given activity. Mrs O reported that she was more motivated and had more opportunities to complete her physiotherapy exercises and task training when she was in her home environment due to the full time support of her carer. This increased task practice gave her the confidence that she was able to perform the set activity.

While this single case study illustrates differences in outcomes between the home and inpatient settings for this patient, there are limitations that must be acknowledged. The timing of the home versus inpatient rehabilitation may also have influenced results. As the home-based setting followed the inpatient setting, it is possible that natural history may account for the improvements seen during the home rehabilitation programme. In addition, some of the information regarding the level of multidisciplinary rehabilitation input Mrs $\mathrm{O}$ received at the first inpatient venue (private hospital) was obtained directly from Mrs $\mathrm{O}$ and her carer. Given the extended length of time Mrs O spent as an inpatient, her report may be subject to recall bias. As such, the amount and timing of interventions from the multidisciplinary rehabilitation team Mrs O received during her first inpatient stay should be viewed with caution. Finally, the relative cost-effectiveness of a rehabilitation programme in the home versus inpatient setting was not done, and would be beneficial in a future study. Lastly, as this single case study offers only level 4 evidence of effectiveness (OCEBM Levels of Evidence Working Group, 2011), no firm conclusions can be drawn regarding the effectiveness of home-based versus inpatient rehabilitation, and clinical interpretation of these findings and application to clinical practice must proceed with caution.

Notwithstanding these limitations, this case study provides preliminary evidence for the effectiveness of home-based compared to inpatient rehabilitation in an older woman with chronic low back pain. Further, it highlights the need for future work in this area, particularly to determine the effects of rehabilitation environment on biopsychosocial outcomes associated with functional impairment.

\section{CONCLUSIONS}

This single case study demonstrated significant differences in functional outcomes for an 81-year-old woman who underwent a rehabilitation programme in both a home and inpatient setting. For some people, the home should not only be considered a place of familiar refuge for the individual, but also a potential location for effective rehabilitation intervention. Contributing factors to the successful outcome for this patient may have included greater empowerment of the individual through differing roles between the patient and therapist, greater patient involvement in goal setting, improved motivation and increased levels of engagement which may be associated with the home environment. Rehabilitation in the home was a more appropriate and effective choice of care for this individual, compared with inpatient rehabilitation.

\section{Conflict of interest: None}

Acknowledgements: The authors would like to thank Dean Byrnes, Senior Pharmacist, Gold Coast Health Service District; the Transitional Care Program, Gold Coast Health Service District

Authoritative information and statistics to promote better health and wellbeing (AIHW) (2007) Older Australians at a glance In: Australian Institute of Health and Welfare (4th ed.) www.aihw.gov.au/publication-detail/?id=6442468045 (accessed 29 October 2012)

Alexander N, Galecki A, Grenier M, Nyquist LV, Hofmeye MR, Grunawalt JC, et al (2001) Task-specific resistance training to improve the ability of activities of daily livingimpaired older adults to rise from a bed and from a chair. $J$ Am Geriatr Soc 49(11): 1418-27

Anderson C, Ni Mhurchu C, Rubenach S, Clark M, Spencer C, Winsor A (2000a) Home or hospital for stroke rehabilitation? Results of a randomized controlled trial II: cost minimisation at 6 months. Stroke 39(5): 1032-7

Anderson C, Rubenach S, Ni Mhurchu C, Clark M, Spencer C, Winsor A (2000b) Home or hospital for stroke rehabilitation? Results of a randomized controlled trial I: Health outcomes at 6 months. Stroke 31: 1024-31

Arnetz J, Almin I, Bergstrom K, Franzen Y, Nilsson H (2004) Active patient involvement in the establishment of physical therapy goals: effects on treatment outcome and quality of care. Adv Physiother 6(2): 50-69

Rossi S (ed) (2012) Australian Medicines Handbook 2012 Australian Medicines Handbook Pty Ltd, Adelaide

Bloom L, Lapierre N, Wilson K, Curran D, Deforge D, Blackmere J (2006) Concordance in goal setting between patients with multiple sclerosis and their rehabilitation team. Am J Phys Med Rehabil 85(10): 807-13

Cunliffe A, Gladman J, Husbands S, Miller P, Dewey M, Harwood R (2004) Sooner and Healthier: a randomised controlled trial and interview study of an early discharge rehabilitation service for older people. Age Ageing 33(3): 246-52

Dworkin RH, O'Connor AB, Backonja M, Farrar JT, Finnerup NB, Jensen TS et al (2007) Pharmacologic management of neuropathic pain: evidence-based recommendations. Pain 132(3): 237-51

Dwyer J, Jackson T (2001) Literature review: Integrated bed and patient management. In: Department of Health Services. Victoria. www.health.vic.gov.au/emergency/ bgdocs/litrview.pdf (accessed 29 October 2012).

Eckert J, Morgan L, Swamy N (2004) Preferences for receipt of care amoung community-dwelling adults. J Aging Soc 
Policy 16(2): 49-65

Fänge A, Ivanoff SD (2009) The home is the hub of health in very old age: Findings from the ENABLE-AGE Project Arch Gerontol Geriatr 48(3): 340-5

Flinders Consulting (2008) National evaluation of the Transition Care Program. RFT 206/0506 Final Evaluation Report 31 May. Commonwealth, State and Territory governments. www.health.gov.au/internet/main/publishing.nsf/ Content/ageing-transition-national-evaluation-report.htm (accessed 29 October 2012)

Kuys S, Brauer S (2006) Validation and reliability of the Modified Elderly Mobility Scale. Australas J Ageing 25(3): $140-4$

Leach M (2005) Rapport: a key to treatment success. Complement Ther Clin Pract 11(4): 262-5

Lee L, Arthur A, Avis M (2008) Using self-efficacy theory to develop interventions that help older people overcome psychological barriers to physical activity: a discussion paper. Int J Nurs Stud 45(11): 1690-9

Mayo NE, Wood-Dauphinee S, Côté R, Gayton D, Carlton J, Buttery J et al (2000) There's no place like home: An evaluation of early supported discharge for stroke. Stroke 31(5): 1016-23

Oxford Centre for Evidence Based Medicine (2011) Levels of Evidence System www.cebm.net/index.aspx?o $=5653$ (accessed 29th October 2012)

Peri K, Kerse N, Robinson E, Parsons M, Latham N (2007) Does functionally based activity make adifference to health status and mobility? A randomised controlled trial in residential care facilities (The Promoting Independent Living Study; PILS). Age Ageing 37(1): 57-63

Rensink M, Schuurmans M, Liondeman E, Hafstiensdottir T (2009) Task oriented training in rehabilitation after stroke: systematic review. J Adv Nurs 65(4): 737-54

Shah S, Vanclay F, Cooper B (1989) Improving sensitivity of the Barthel index for stroke rehabilitation. J Clin Epidemiol 42(8): 703-9

Therapeutic Guidelines Limited (2012) eTG complete www. etg.tg.com.au (accessed 29 October 2012)

Von Koch L, Wottrich A, Holmgvist L (1998) Rehabilitation in the home versus the hospital: the importance of context. Disabil Rehabil 20(10): 367-72

Wade DT, Collin C (1987) The Barthel ADL Index: A standard measure of physical disability? Int Disabil Stud 10(2): $64-7$ 